\title{
What are the alternatives to replace the pulmonary root in the absence of pulmonary homografts?
}

\author{
Ravil Sharifulin, Igor Demin, Alexander Karaskov, Alexander Chernyavsky, \\ Alexander Bogachev-Prokophiev \\ E. Meshalkin National Medical Research Centre, Novosibirsk, Russian Federation \\ Correspondence to: Ravil Sharifulin, MD. 15, Rechkunovskaya Street, Novosibirsk, Russian Federation. Email: ravil-sharifulin@rambler.ru.
}

Submitted Sep 04, 2020. Accepted for publication Dec 23, 2020.

doi: $10.21037 /$ acs-2020-rp-18

View this article at: http://dx.doi.org/10.21037/acs-2020-rp-18

The Ross procedure is a unique option for aortic valve replacement, providing excellent survival prospects and quality of life, as well as low rates of bleeding, thromboembolic events and endocarditis. After a period of recession, this operation is again receiving increased attention. The Achilles' heel of the operation is a lifetime risk of right ventricular graft reintervention. Pulmonary allografts are the gold standard for right ventricular outflow tract (RVOT) reconstruction. Nevertheless, for various economic and legal reasons, their availability is limited in some countries. For example, until recently, there were no allograft banks in Russia and small pediatric sizes remain unavailable. In search of a suitable alternative to allografts, different biological and synthetic conduits have been proposed.

There are few studies dedicated to alternative grafts for RVOT reconstruction during the Ross procedure, with relatively few patients and limited observation periods providing contradictory results, and even fewer involving direct comparisons with allografts. It is well-known that RVOT reconstruction results are largely determined by patient age and graft size. In some studies, porcine roots and pericardial xenografts have demonstrated acceptable hemodynamic performance and rates of dysfunction in adults and adolescents at mid-term follow-up (1). However, these promising results were not confirmed in studies with longer follow-up durations, which reported worse results than allografts in terms of dysfunction and reoperation rates $(2,3)$. According to data from the Germany Ross procedure registry, the durability of xenografts in young adults was also unacceptably low (4).

The other xenograft for RVOT reconstruction, bovine jugular vein Contegra (Medtronic Inc., Minneapolis, MN) is the most frequently used alternative conduit in pediatric populations providing off-the-shelf availability of small sizes $(12-22 \mathrm{~mm})$. This conduit demonstrates mid-term durability comparable to allografts, depending on patient age and conduit size (ten-year freedom from reintervention of 50-90\%) (5). The disadvantage of a jugular vein conduit is the higher incidence of endocarditis (6-10\%) compared with other grafts.

To weaken the patient's immune reaction against cell antigens and increase graft durability, decellularized xenografts are being developed. However, they have recently demonstrated unsatisfactory results compared to decellularized allografts, which may be due to the disadvantages of the decellularization approach (6). Christ et al. 2017, in one of the largest studies on xenografts for RVOT reconstruction during the Ross procedure ( $\mathrm{n}=492$ adults), showed decellularized porcine pulmonary roots had a high rate of reoperation due to structural failure $(58.6 \%$ ten-year freedom from RVOT reoperation) and low survival rate (70.4\% at ten years). Nevertheless, tissue engineering is a promising avenue of medical science and development of the ideal biomaterial continues.

Another alternative conduit for RVOT reconstruction is polytetrafluoroethylene (PTFE) prostheses. These conduits were expected to be completely resistant to calcification. Nevertheless, histological examination of explanted PTFE grafts has shown that, over time, they also undergo calcium degeneration, although less pronounced compared to biological prostheses (7). The largest multicenter study on hand-made PTFE conduits in Japan ( $\mathrm{n}=902$ patients) revealed excellent ten-year freedom from reoperation of $95.1 \%$ for patients older than two years (7). Nevertheless, the follow-up periods for all published PTFE conduit 
studies are relatively short and require further analysis.

Neonates and infants represent another group of patients undergoing the Ross procedure, and require earlier conduit exchange due to somatic outgrowth. Allografts, bovine jugular vein, and pericardial conduits have shown comparable low freedom from reintervention in these patients (8). PTFE valved conduits have demonstrated promising results in patients younger than two years, with similar durability to allografts (9). Considering this, alongside availability and cost, xenografts and PTFE conduits can currently be considered an acceptable alternative to allografts in this age category.

In our center, we have over 800 procedures-worth of experience in applying different biological conduits with various anticalcium treatments for RVOT reconstruction during the Ross procedure. We found that aortic porcine root in the adult population demonstrated an unacceptably high rate of dysfunction and reoperation $(80.6 \%$ tenyear freedom from reinterventions), which we explain by the elastic fiber content in aortic wall tissue being more susceptible to calcification (10). Glutaraldehyde-treated pericardial xenografts also had significantly lower durability than did allografts $(82.7 \%$ vs. $100 \%$ ten-year freedom from reinterventions), while durability of diepoxidetreated pericardial xenografts did not differ significantly (96.8\%) (10). In addition, our experimental data confirm the clinical results that glutaraldehyde has a lower mineralization-blocking efficacy than the diepoxy compound ethylene glycol diglycidyl (11). However, diepoxidetreated pericardial xenografts had significantly higher postoperative RVOT gradients and gradient progression rates than allografts, which may predict more xenograft dysfunctions in the future. Moreover, we found that the rate of dysfunction for all types of xenografts was significantly lower in patients older fifty years. In the pediatric group (301 children; mean age 2.3 years; mean follow-up 4.2 years), there were no differences in freedom from reintervention for porcine aortic conduit, glutaraldehyde-treated bovine jugular vein, or pericardial valved conduits, which were all $70.6 \%$ at six years. We have limited experience of using commercial PTFE conduits for RVOT reconstruction (twenty-eight implantations; mean follow-up duration four years). We did not observe any dysfunction at mid-term follow-up, although the RVOT gradients were higher than those that occurred when using allografts.

In conclusion, pulmonary allografts remain the gold standard for RVOT reconstruction. Currently, existing alternative conduits show worse long-term results or roughly comparable mid-term results and require an assessment of long-term durability. The results of all conduits in young children are not satisfactory. The search for the best conduit for RVOT reconstruction continues. We have high expectations that tissue engineering will create an ideal conduit resistant to degeneration with regenerative capacity and growth potential. Meanwhile, alternative conduits should be used with caution for RVOT reconstruction during the Ross procedure. We have changed our RVOT conduit selection policy and do not currently recommend the use of alternative conduits in adolescents or young adults. Nevertheless, we consider that the use of alternative substitutes is possible in certain patient groups when allografts are not available, such as young children or a limited group of patients over fifty years.

\section{Acknowledgments}

Funding: None.

\section{Footnote}

Conflicts of Interest: The authors have no conflicts of interest to declare.

Open Access Statement: This is an Open Access article distributed in accordance with the Creative Commons Attribution-NonCommercial-NoDerivs 4.0 International License (CC BY-NC-ND 4.0), which permits the noncommercial replication and distribution of the article with the strict proviso that no changes or edits are made and the original work is properly cited (including links to both the formal publication through the relevant DOI and the license). See: https://creativecommons.org/licenses/by-nc-nd/4.0/.

\section{References}

1. Juthier F, Vincentelli A, Hysi I, et al. Stentless porcine bioprosthesis in pulmonary position after Ross procedure: midterm results. Ann Thorac Surg 2015;99:1255-9.

2. Christ T, Claus B, Woythal N, et al. The Ross procedure in adults: long-term results of homografts and stentless xenografts for pulmonary valve replacement. Thorac Cardiovasc Surg 2017;65:656-61.

3. Bell D, Prabhu S, Betts KS, et al. Long-term performance of homografts versus stented bioprosthetic valves in the pulmonary position in patients aged 10-20 years. Eur J Cardiothorac Surg 2018;54:946-52. 
4. Sievers HH, Stierle U, Charitos EI, et al. A multicentre evaluation of the autograft procedure for young patients undergoing aortic valve replacement: update on the German Ross Registry. Eur J Cardiothorac Surg 2016;49:212-8.

5. Patel PM, Tan C, Srivastava N, et al. Bovine jugular vein conduit: a mid- to long-term institutional review. World J Pediatr Congenit Heart Surg 2018;9:489-95.

6. Christ T, Paun AC, Grubitzsch H, et al. Long-term results after the Ross procedure with the decellularized AutoTissue Matrix P bioprosthesis used for pulmonary valve replacement. Eur J Cardiothorac Surg 2019;5 5:885-92.

7. Miyazaki T, Yamagishi M, Maeda Y, et al. Long-term outcomes of expanded polytetrafluoroethylene conduits with bulging sinuses and a fan-shaped valve in right ventricular outflow tract reconstruction. J Thorac Cardiovasc Surg 2018;155:2567-76.

Cite this article as: Sharifulin R, Demin I, Karaskov A, Chernyavsky A, Bogachev-Prokophiev A. What are the alternatives to replace the pulmonary root in the absence of pulmonary homografts? Ann Cardiothorac Surg 2021;10(4):524526. doi: 10.21037/acs-2020-rp-18
8. Vitanova K, Cleuziou J, Hörer J, et al. Which type of conduit to choose for right ventricular outflow tract reconstruction in patients below 1 year of age? Eur J Cardiothorac Surg 2014;46:961-6.

9. Mercer CW, West SC, Sharma MS, et al. Polytetrafluoroethylene conduits versus homografts for right ventricular outflow tract reconstruction in infants and young children: An institutional experience. J Thorac Cardiovasc Surg 2018;155:2082-2091.e1.

10. Sharifulin R, Bogachev-Prokophiev A, Demin I, et al. Allografts and xenografts for right ventricular outflow tract reconstruction in Ross patients. Eur J Cardiothorac Surg 2020;ezaa244. [Epub ahead of print]. doi:10.1093/ejcts/ ezaa244.

11. Zhuravleva IY, Nichay NR, Kulyabin YY, et al. In search of the best xenogeneic material for a paediatric conduit: an experimental study. Interact CardioVasc Thorac Surg 2018;26:738-44. 